\title{
Randomized study evaluating testosterone recovery using short- versus long-acting luteinizing hormone releasing hormone agonists
}

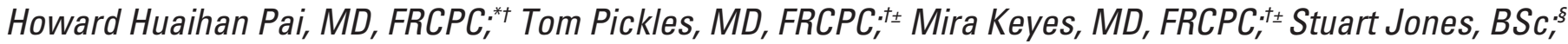 \\ Rachel E. McDonald, BSc, ${ }^{*}$ Mary Lesperance, Ph D, PStat, Eric Berthelet, MD, FRCPC; ${ }^{; \pm}$
}

*Radiation Oncology Program, British Columbia Cancer Agency, Victoria, BC; †Department of Surgery, Faculty of Medicine, University of British Columbia, Vancouver, BC; ${ }^{+}$Radiation Oncology Program, British Columbia Cancer Agency-Vancouver Centre, Vancouver, BC; $\$$ Flinders University School of Medicine, Adelaide, Australia; * Sydney Medical School, University of Sydney, Sydney, Australia; "Department of Mathematics and Statistics, University of Victoria, Victoria, BC

See related article on page 180.

Cite as: Can Urol Assoc J 2011;5(3):173-9; D01:10.5489/cuaj.10102

\section{Abstract}

Introduction: We sought to compare the rate of return of testosterone levels and sexual function in men with prostate cancer receiving longer acting, 3-month preparation of luteinizing hormone-releasing hormone agonist (L-LHRH-A) versus shorter acting, 1-month preparation of luteinizing hormone-releasing hormone agonist (S-LHRH-A).

Methods and Materials: Men with low to intermediate risk localized prostate cancer were randomized to either L-LHRH-A (2-3 month duration LHRH-A) or S-LHRH-A (6-1 month duration LHRH-A) of androgen suppression therapy (AST) and prostate brachytherapy using iodine-125 radioisotopes. Serum total testosterone levels and PSA were recorded every 2 months for 2 years.

Results: A planned target sample size of 100 was not achieved due to insufficient accrual. A total of 55 patients were randomized and 46 were used for analysis. The median time to recovery of testosterone to baseline levels (calculated from end of AST) was 8 and 4 months in the L-LHRH-A and S-LHRH-A arms, respectively $(p=0.268)$. The median time to testosterone recovery to lower limit of reference range was 4 and 2 months respectively ( $p=0.087$ ). Interpretation: This randomized study, which failed to reach accrual target, showed a trend towards more rapid recovery of testosterone levels using shorter acting LHRH-A. Another randomized study would be required to validate these findings. Currently, there is insufficient evidence to recommend the use of shorter acting LHRH-A as a means of providing more rapid recovery of testosterone levels.

\section{Résumé}

Introduction : Nous avons voulu comparer la vitesse de retour des taux de testostérone et de la fonction sexuelle chez des hommes atteints d'un cancer de la prostate recevant un agoniste de la LHRH à longue durée d'action pendant 3 mois ou un agoniste de la LHRH à courte durée d'action pendant 1 mois.
Matériel et méthodologie : Des hommes atteints d'un cancer de la prostate localisé avec risque faible à intermédiaire ont été randomisés pour recevoir soit un agoniste de la LHRH à longue durée d'action (2 doses trimestrielles) soit un antagoniste de la LHRH à courte durée d'action ( 6 doses mensuelles) comme traitement antiandrogène et une brachythérapie prostatique avec des radioisotopes de l'iode 125. Les taux sériques de testostérone totale et d'APS ont été notés tous les 2 mois pendant 2 ans.

Résultats : L'échantillon prévu au départ de 100 patients n'a pu être obtenu en raison d'un recrutement insuffisant. Au total, 55 patients ont été randomisés et 46 ont été inclus dans les analyses. L'intervalle médian de retour à des taux normaux de testostérone (calculés à partir de la fin du traitement antiandrogène) était de 8 et 4 mois dans les groupes sous agoniste de la LHRH à longue et à courte durée d'action, respectivement $(p=0,268)$. L'intervalle médian requis pour que les taux de testostérone atteignent la limite inférieure des valeurs de référence était de 4 et 2 mois, respectivement $(p=0,087)$.

Interprétation : Cette étude randomisée, où on n'a pas réussi à obtenir le nombre de patients voulu, a montré une tendance vers un retour plus rapide des taux de testostérone avec un traitement par agoniste de la LHRH à courte durée d'action. Une autre étude randomisée serait nécessaire pour valider ces résultats. Actuellement, on ne dispose pas de suffisamment de données pour recommander un agoniste de la LHRH à courte durée d'action comme moyen pour ramener les taux de testostérone plus rapidement à la normale.

\section{Introduction}

Luteinizing hormone releasing-hormone agonists (LHRH-A) are widely used as androgen suppression therapy (AST) for localized and metastatic prostate cancer. Several randomized studies have demonstrated improved cure rates when AST is combined with radiation therapy, particularly for unfavourable risk localized prostate cancer. ${ }^{1,2}$ Luteinizing hormone releasing-hormone agonists are also used in a neoadjuvant fashion in men undergoing brachytherapy who require prostate gland downsizing. Androgen suppression therapy has also been used in conjunction with brachytherapy for men with intermediate-risk disease at our institution. 
Pai et al.

Luteinizing hormone releasing-hormone agonists cause serum testosterone levels to fall to castrate range, resulting in many unwanted temporary side effects, such as vasomotor instability causing hot flushes, fatigue, impaired libido, sexual function and cognition, emotional distress, decreased bone density and metabolic syndrome. Androgen suppression therapy has also been linked to long-term effects, such as diabetes mellitus and cardiovascular disease..$^{3,4} \mathrm{~A}$ rapid return of serum testosterone levels following completion of AST in this respect is desirable.

Several series have reported rate of testosterone recovery after cessation of AST to be in the median range of 4 to 15 months. ${ }^{5-12}$ Pickles and colleagues noted a median recovery time for testosterone of 10 months for men receiving between 3 months to 3 years of LHRH-A. ${ }^{10}$ Interestingly, the median time to recovery of testosterone for men who received the 3-month preparation of $\mathrm{LHRH}$-A was 16 months compared to only 8 months for those men who received the shorter 1-month preparation of LHRH-A. This study suggested that men who receive shorter preparation of LHRH-A may achieve a quicker recovery of their testosterone levels and, along with it, a shorter duration of side effects from androgen suppression at the inconvenience of more frequent injections.

To validate the findings from the retrospective study by Pickles and colleagues, ${ }^{10}$ a randomized controlled trial was undertaken to determine if different preparations of LHRH-A affected the rate of normalization of testosterone levels following cessation of AST.

\section{Materials and methods}

We obtained approval by the local institutional research ethics board in May 2003. The primary objective of the study was to measure and compare the rate of return of serum total testosterone levels in men with a diagnosis of localized prostate cancer, who were scheduled to receive 6 months total of AST in combination with prostate brachytherapy at the British Columbia (BC) Cancer Agency in British Columbia, Canada. Men were randomized to either $6 \times 1$-month preparations of LHRH-A (using leuprolide acetate) or $2 \times$ 3-month preparations of LHRH-A. Secondary objectives included measurement of prostate-specific antigen (PSA), sexual function and urinary function bother.

\section{Patient eligibility}

Men with biopsy-proven favourable risk or intermediate risk localized prostate adenocarcinoma who elected to undergo prostate brachytherapy were eligible. Favorable risk was defined as satisfying all of the following: clinical T-stage $\leq \mathrm{T} 2 \mathrm{C}$ (using the 1997 American Joint Committee on Cancer TNM staging system), and Gleason score $\leq 6$ and presenting
PSA $<10 \mathrm{ng} / \mathrm{mL}$. Intermediate risk was defined as: T-stage $\leq \mathrm{T} 2 \mathrm{c}$, (Gleason score $<7$ and PSA $10-15 \mathrm{ng} / \mathrm{mL}$ ) or (Gleason score 7 and PSA $<10 \mathrm{ng} / \mathrm{mL}$ ). Using the BC Cancer Agency Prostate Brachytherapy guidelines during that era, in men with favourable risk disease, only those with large prostate gland volume over $50 \mathrm{cc}$ (as measured by transrectal ultrasound who required AST for prostate gland cytoreduction prior to prostate brachytherapy) were eligible for this study. All men with intermediate-risk disease undergoing prostate brachytherapy required AST according to the existing guidelines. Patients also had to satisfy the BC Cancer Agency guidelines for prostate brachytherapy, including all of the following: a life expectancy of at least 5 years, no history of other active malignancies within the last 5 years other than non-melanoma cutaneous carcinomas, no history of transurethral resection of prostate, no active bleeding disorders and suitable for general, spinal or local anaesthesia.

\section{Treatment}

Androgen suppression therapy in all patients began about 3 months before brachytherapy. The control arm received the $2 \times 3$-month preparation of LHRH-A (L-LHRH-A) using leuprolide acetate, given intramuscularly. The experimental arm received $6 \times 1$-month duration of $\mathrm{LHRH}-\mathrm{A}$ (S-LHRH-A). All patients also received flutamide, $250 \mathrm{mg}, 3$ times daily for 4 weeks total; this was administered with the first injection of leuprolide. After informed written consent, study patients were randomized to either L-LHRH-A or S-LHRH-A.

Prostate brachytherapy used the technique of pre-planned, real-time, transrectal ultrasound guidance, with transperineal insertion of preloaded needles containing I-125 radioisotopes. Minimum peripheral dose was prescribed at $144 \mathrm{~Gy}$ to a planned target volume encompassing the prostate gland with a peri-prostatic margin between 0 to $5 \mathrm{~mm}$ and with planned urethral sparing. The technique has been previously described. ${ }^{13,14}$

\section{Assessment}

Study patients had serum levels for PSA and total testosterone drawn prior to commencement of AST and then every 2 months for 2 years after start of AST. Patients were also given questionnaires regarding sexual function (using the International Index of Erectile Function ${ }^{15}$ ) and urinary function bother (using the International Prostate Symptom Score) to complete at the same time intervals as their blood tests; these scores are not reported here. 
Evaluating testosterone recovery

\section{Statistical considerations}

The primary endpoint was time to recovery of testosterone; this was measured as starting 6 months after the first LHRH-A injection was given (i.e., at the completion of the planned duration of AST). A minimum of 35 patients per treatment arm (70 in total) were required to have an $80 \%$ power of detecting a true difference in primary outcome with of 0.05. This was based on the observation from Pickles and colleagues that the median time to recovery of testosterone in men receiving $\mathrm{S}-\mathrm{LHRH}-\mathrm{A}$ was 8 months and half the time compared to men receiving $\mathrm{L}-\mathrm{LHRH}-\mathrm{A}$ who had a median testosterone recovery of 16 months. ${ }^{10} \mathrm{~A}$ target sample size of 100 was chosen to account for patients found to be ineligible for study after registration, lost to follow-up or unable to complete prescribed treatment. We anticipated an accrual period of 12 months based on the prior years' brachytherapy program numbers.

Pearson's chi-square test of homogeneity and MannWhitney test were used to compare the distributions of factors between treatment groups (Table 1). Kaplan-Meier survival curves and log-rank tests of homogeneity were used to evaluate the effect of candidate factors on outcomes. Associations between candidate factors and outcomes were modelled using Cox proportional hazards regression, ${ }^{16}$ with SPSS Version 17.0 (IBM Corporation, Somers, NY). A $p$ value of $\leq 0.05$ was considered statistically significant.

\section{Results}

The study was closed without meeting its targeted sample size of 100 due to slow accrual. Accrual was slower than anticipated mainly due to a reduction in the usage of AST during the accrual period; the provincial guidelines changed regarding the size criteria of the prostate gland that would require AST for prostate gland size reduction prior to prostate brachytherapy. At the beginning of the study, about $60 \%$ of men received AST with prostate brachytherapy; this figure declined to about $20 \%$ near the closure of the study. A total of 55 patients were enrolled in the study over 2.5 years beginning in January 2004. Nine patients were excluded, leaving a total of 46 who were included in the analysis. Of these 9 excluded patients, 2 of them were excluded because they did not receive the intended hormone therapy preparation and had limited follow-up information; 2 were excluded because they did not receive brachytherapy; another 2 patients were excluded because they did not have baseline testosterone measurements recorded; the remaining 3 patients were excluded due to insufficient follow-up data and blood measurements.

Patient and tumour characteristics were recorded (Table $1)$. There were a higher proportion of men $\geq 65$ years of age in the L-LHRH-A arm compared to the S-LHRH-A arm.

\begin{tabular}{|c|c|c|c|}
\hline \multirow[t]{2}{*}{ Variable } & L-LHRH-A & S-LHRH-A & $\begin{array}{l}\text { Chi-square } \\
\text { test } p \text { value }\end{array}$ \\
\hline & \multicolumn{2}{|c|}{ Value (range) } & \\
\hline No. patients & 22 & 24 & \\
\hline Median age, yr & $\begin{array}{c}69 \\
(57-80.9)\end{array}$ & $\begin{array}{c}65 \\
(50-76.5)\end{array}$ & $0.107^{*}$ \\
\hline$\%$ patients $\geq 65$ years old & $68 \%(15 / 22)$ & $50 \%(12 / 24)$ & 0.171 \\
\hline Pre-treatment PSA (ng/mL) & $\begin{array}{c}6.4 \\
(0.9-9.4)\end{array}$ & $\begin{array}{c}7.2 \\
(2.0-16.0)\end{array}$ & $0.450^{*}$ \\
\hline $\begin{array}{l}\text { Median baseline } \\
\text { testosterone (nmol/L) }\end{array}$ & $\begin{array}{c}13.6 \\
(8.8-23.0)\end{array}$ & $\begin{array}{c}13.0 \\
(5.5-36.0)\end{array}$ & $0.800 *$ \\
\hline $\begin{array}{l}\% \text { sub-normal baseline } \\
\text { testosterone }\end{array}$ & $0 \%(0 / 22)$ & $4 \%(1 / 24)$ & 0.522 \\
\hline Baseline IIEF & $34(6-75)$ & $60(6-71)$ & $0.116^{*}$ \\
\hline \multirow[t]{2}{*}{ Baseline IPSS } & $6(2-11)$ & $5(0-21)$ & $0.609 *$ \\
\hline & \multicolumn{3}{|c|}{$\%$ (number) } \\
\hline \multicolumn{4}{|l|}{ Gleason score } \\
\hline$\leq 6$ & $59 \%(13 / 22)$ & $54 \%(13 / 24)$ & \multirow{2}{*}{0.485} \\
\hline 7 & $41 \%(9 / 22)$ & $46 \%(11 / 24)$ & \\
\hline \multicolumn{4}{|l|}{ T stage } \\
\hline T1 & $46 \%(10 / 22)$ & $50 \%(12 / 24)$ & \multirow{2}{*}{0.495} \\
\hline T2 & $54 \%(12 / 22)$ & $50 \%(12 / 24)$ & \\
\hline \multicolumn{4}{|l|}{ Risk group } \\
\hline Low & $54 \%(12 / 22)$ & $42 \%(10 / 24)$ & \multirow{2}{*}{0.282} \\
\hline Intermediate & $46 \%(10 / 22)$ & $58 \%(14 / 24)$ & \\
\hline \multicolumn{4}{|l|}{ Percent positive cores } \\
\hline$<50$ & $68 \%(15 / 22)$ & $62 \%(15 / 24)$ & \multirow{2}{*}{0.463} \\
\hline$\geq 50$ & $32 \%(7 / 22)$ & $38 \%(9 / 24)$ & \\
\hline \multicolumn{4}{|c|}{$\begin{array}{l}\text { L-LHRH-A = Long preparation ( } 3 \text { month) luteinizing hormone- releasing hormone agonist; } \\
\text { S-LHRH-A = short preparation ( } 1 \text { month) luteinizing hormone-releasing hormone agonist; } \\
\text { PSA = prostate-specific antigen; IIEF = International Index of Erectile Function; } \\
\text { IPSS = International Prostate Symptom Score; *Mann-Whitney test for significant difference } \\
\text { for continuous-type variables. }\end{array}$} \\
\hline
\end{tabular}

However, using Chi-square testing for categorical variables and Mann-Whitney testing for continuous type variables, there were no statistically significant imbalances in factors between treatment arms.

\section{Testosterone recovery and PSA response}

Not all study patients completed all 12 blood tests as stipulated by the protocol due to poor adherence to blood testing schedule. Only $45 \%$ and $29 \%$ of men completed all of the required blood tests in the L-LHRH-A and S-LHRH-A arms, respectively. Eighty-two percent and $66 \%$ of patients completed at least $77 \%$ of required blood tests, respectively. A Pearson's chi-square test of homogeneity was performed and failed to detect an imbalance in proportion of completed blood tests between treatment arms $(p=0.181)$.

Testosterone levels dropped to castrate levels in all patients following AST followed by full or partial recovery. We recorded the median testosterone levels at each time interval grouped by treatment arm (Fig. 1). The median time 
Pai et al.

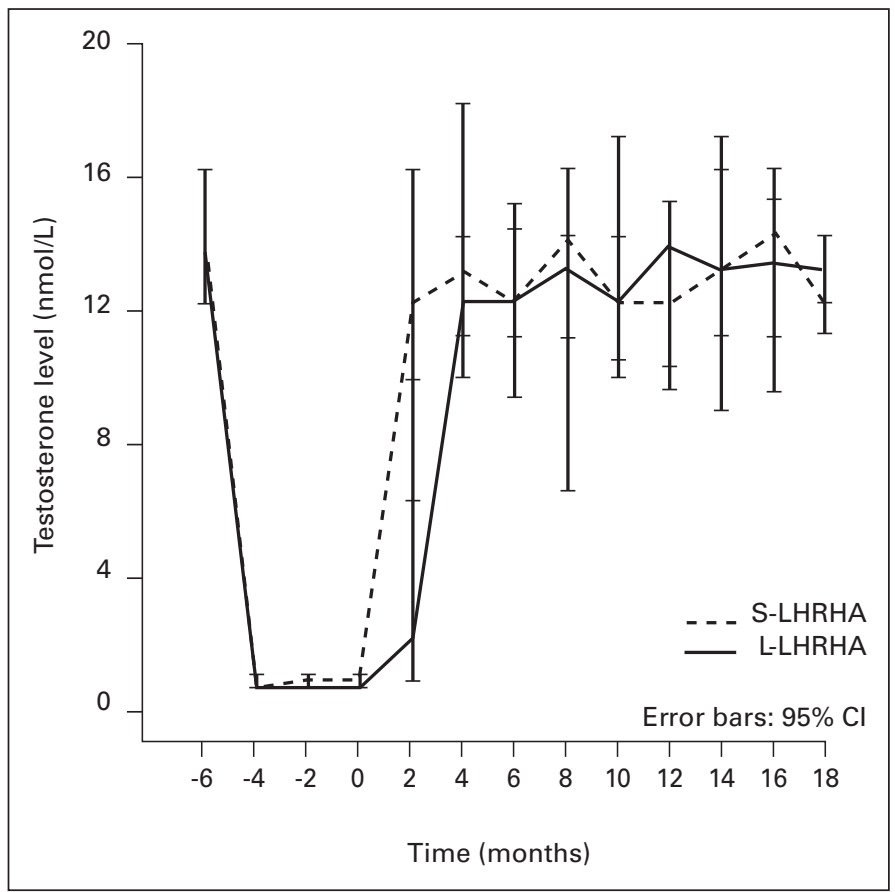

Fig. 1. Median testosterone levels grouped by treatment arm (Time @ -6 months $=$ baseline testosterone level and first luteinizing hormone-releasing hormone agonist (LHRH-A) injection; time @ 0 months = end of LHRH-A treatment).

to recovery of testosterone levels to baseline (i.e., pre-treatment) from end of AST was 8 months and 4 months for the L-LHRH-A and S-LHRH-A arms respectively (log-rank test, $p=0.268$ ) (Table 2). Thirty-two percent (7 of 22) and $21 \%$ ( 5 of 24) of men did not have recovery of their testosterone levels after AST to baseline values in the L-LHRH-A and S-LHRH-A arms, respectively. The last testosterone measurement was taken 24 months after first LHRH-A injection was given. Additional testosterone measurements beyond 24 months were not recorded. It cannot be ruled out that some patients' testosterone levels may have recovered beyond 24 months of testing. The median time to recovery of testosterone levels to lower limit of reference range calculated from end of AST was 4 months and 2 months for L-LHRH-A and S-LHRH-A arms, respectively (log-rank test, $p=0.087$ ). Only 1 patient from the L-LHRH-A arm did not have recovery of his testosterone levels to the lower limit of the reference range. The cumulative proportion of patients who recover their testosterone level after AST was plotted versus time and computed using the Kaplan-Meier method (Fig. 2). Although not statistically significant, there was a trend towards faster recovery time to lower limit of reference range of testosterone favouring the S-LHRH-A arm. The median time to PSA nadir was 6 months for both treatment arms (calculated from the start of AST).

The primary endpoints from the end of AST to recovery of testosterone to baseline and to lower limit were modelled using Cox proportional hazards model. Five variables were
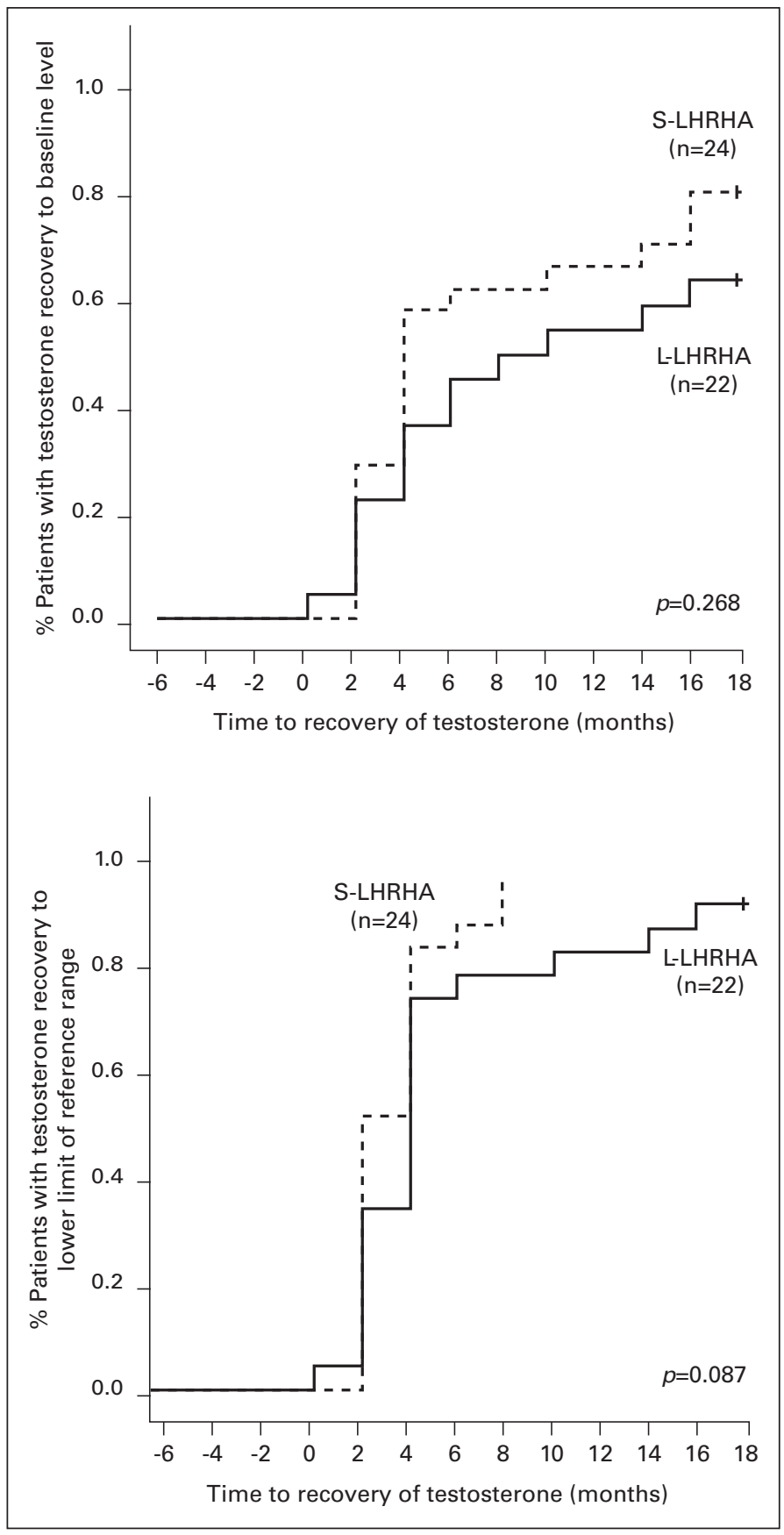

Fig. 2. Kaplan Meier curves of proportion of patients with testosterone recovery to (a) baseline levels, (b) lower limit of reference range. ( $p$-value calculated by log-rank testing). (Time @ -6 months = baseline testosterone level and first luteinizing hormone-releasing hormone agonist (LHRH-A) injection; time @ 0 months $=$ end of LHRH-A treatment).

used in the model including treatment arm, categorical age ( $<65$ years, $\geq 65$ years of age), Gleason score ( $<7$ vs. 7$)$, risk category (low vs. intermediate) and percent positive cores ( $<50 \%$ vs. $\geq 50 \%$ ). The hazard ratios (with $95 \%$ confidence intervals) for S-LHRH-A versus L-LHRH-A were 1.175 $(0.590,2.339)$ and $1.531(0.789,2.971)$ for time to baseline 


\begin{tabular}{|c|c|c|c|}
\hline Variable & L-LHRH-A & S-LHRH-A & $p$ value \\
\hline$\%$ Achieving baseline testosterone level & $64 \%(14 / 22)$ & $79 \%(19 / 24)$ & $0.200^{*}$ \\
\hline$\%$ Achieving lower limit of reference range of testosterone level & $96 \%(21 / 22)$ & $100 \%(24 / 24)$ & $0.478^{*}$ \\
\hline Median time to recovery to baseline testosterone level (months) ${ }^{\dagger}$ & $8(0-18)$ & $4(2-18)$ & $0.268^{\ddagger}$ \\
\hline Median time to recovery to lower limit of reference range of testosterone levels (months) & $4(0-18)$ & $2(2-8)$ & $0.087^{\ddagger}$ \\
\hline
\end{tabular}

testosterone and lower limit of testosterone, respectively. None of the hazard ratios for either outcome were statistically significant. It is worth noting that for this study, a hazard ratio of $>1$ was indicative of shorter times to recovery versus the reference group.

\section{Discussion}

Several series have described the rate of recovery of testosterone levels following AST. ${ }^{5-11}$ Factors that may influence the rate of recovery include age $\mathrm{e}^{5,6,8,10}$ and race, ${ }^{5}$ duration of LHRH-A therapy, ${ }^{9,11,17}$ baseline testosterone levels, ${ }^{5,8,10}$ type of AST agents used ${ }^{10}$ and the type of LHRH-A preparation used. ${ }^{10}$ To minimize the duration of side effects and longterm risks of androgen suppression, an appealing strategy is to use preparations of LHRH-A that could potentially hasten the recovery of testosterone levels after completion of AST. Another strategy is to use non-steroidal anti-androgens alone. ${ }^{18}$ We are intrigued with the type of $\mathrm{LHRH}-\mathrm{A}$ preparation used and its effect on rate of testosterone recovery. In a retrospective analysis by Pickles and colleagues, ${ }^{10} 49$ men who were treated with curative intent with external radiation therapy received treatment with the 1-month preparation of LHRH-A for a median duration of 9 months (range: 3-26 months). Another 68 men who received radiation therapy were given the 3-month preparation of LHRH-A for a median duration 11 months (range: 3-35 months). Additionally, 150 men received cyproterone acetate/stilbestrol (CPA/DES) for a median duration of 7 months (range: 3-34 months). Total testosterone measurements were obtained 6 weeks after completion of radiation, then every 6 months for 3 years and yearly thereafter. Interestingly, the median time to recovery of testosterone levels to the lower limit reference range calculated from the end of AST was 7, 8 and 16 months for the groups receiving CPA/DES, 1 month preparation of $\mathrm{LHRH}-\mathrm{A}$ and 3 month preparation of LHRH-A, respectively. On multivariable analysis, factors associated with a delay in testosterone recovery were advanced age, low baseline testosterone level and use of the 3-month preparation of LHRH-A. However, there were some imbalances in the distribution of factors between the 2 groups of patients receiving different $\mathrm{LHRH}-\mathrm{A}$ preparations that may have influenced the results. For example, men who received the 3-month preparation of LHRH-A were more likely to be elderly and receive a longer duration of AST. Thus, the observation that men who received longer preparation of LHRH-A had a slower recovery of testosterone was only hypothesis-generating from this retrospective series; our intent with this present randomized study was to validate these findings.

In this study, the median time to recovery of testosterone to baseline value was twice as long for the L-LHRH-A arm (8 months) compared to the S-LHRH-A arm (4 months). However, this result was not statistically significant. The median time to recovery of testosterone to lower limit of reference range was again twice as long for the L-LHRH-A arm (4 months) compared to the S-LHRH-A arm (2 months). This was not statistically significant, but a trend was noted favouring faster recovery using S-LHRH-A $(p=0.087)$. A Cox multivariable analysis failed to identify the treatment arm as a significant predictor of time to recovery of testosterone.

There are several possible explanations why we did not observe a statistically significant difference in rate of testosterone recovery, despite a trend observed favouring faster recovery in the patients receiving S-LHRH-A. The study did not reach the planned sample size of 100 and may not have had enough power to detect a statistically significant difference in outcome. Additionally, measurements of testosterone were incomplete in many patients. For example, only $29 \%$ and $45 \%$ of patients in the short-acting and longacting preparations, respectively, had full testosterone levels available. This raises concern that the data collected may not necessarily be representative of the entire cohort of men, given that in both arms only a minority of patients actually completed the all the blood testing. Note that the Pearson's chi-square test of homogeneity did not reveal any imbalance in the percent of completed blood tests between treatment arms, which could have biased results. Perhaps a statistically significant difference in testosterone recovery rates could have been detected, with a larger sample size and a more complete set of blood results. However, one may argue whether the observed difference of 2 months to the lower limit of reference range between treatment arms is clinically significant and worth the additional injections required to give the 1 -month preparations. Our testosterone recovery results share some similarities to that of Pickles and colleagues. ${ }^{10}$ The difference in testosterone recovery to the lower limit of reference range between treatment arms was by a factor of 2 . However, there is considerable difference 
Pai et al.

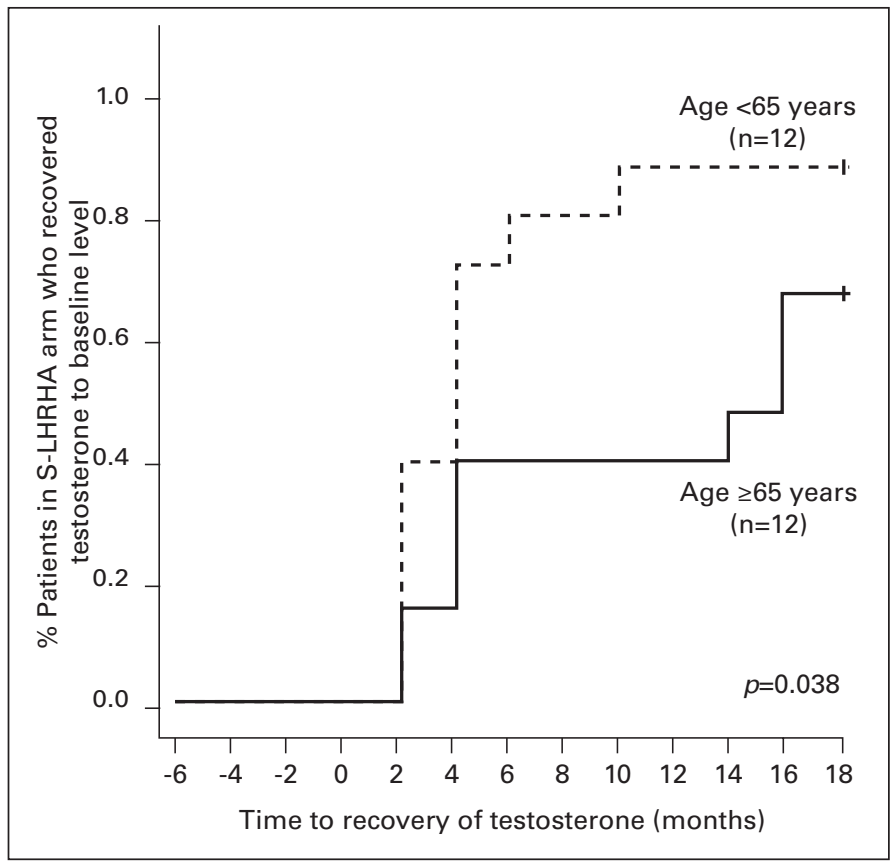

Fig. 3. Kaplan Meier curves of proportion of patients in the short-acting luteinizing hormone-releasing hormone agonist ( $\mathrm{LHRH}-\mathrm{A}$ ) treatment arm with testosterone recovery to baseline level in men $<65$ years or $(n=12)$ or $\geq 65$ years of age $(n=12)$. (Time @ -6 months = baseline testosterone level and first LHRH-A injection; time @ 0 months = end of LHRH-A treatment).

in the absolute time to recovery between the 2 studies. For example, in the Pickles' retrospective study, the median time to testosterone recovery to the lower limit reference range was 16 and 8 months for the L-LHRH-A and S-LHRH-A groups, respectively. In our study, the corresponding times were 4 and 2 months, respectively. We noted, however, that the testosterone measurements in Pickles study were done 6 weeks post-radiotherapy and then every 6 months, which is considerably less frequent than every 2 months, as in this current study. The longer duration between testosterone testing in the Pickles study may have resulted in prolongation of the recovery rates. This further makes comparisons of our results to Pickles difficult to make. Additionally, it is difficult to compare our recovery rates to those reported by other investigators given the heterogeneity in age distribution of patients, dosing, duration and the type of hormonal agents used between studies and the different definitions used for testosterone recovery. Our results are more congruent with those of Gulley and colleagues who reported a median recovery time to the lower limit of reference range of 4 months, in keeping with our results in the L-LHRH-A arm. ${ }^{8}$ In that study, men also received 6 months of the 3-month preparation of LHRH-A, along with thalidomide or placebo thereafter. Furthermore, in a study by Oefelein and colleagues, a small series of patients received a single 3-month preparation of $\mathrm{LHRH}-\mathrm{A} \pm$ flutamide prior to prostatectomy or external beam radiotherapy. ${ }^{12}$ The median time to testos- terone recovery was 4 months after cessation of LHRH-A therapy. The discrepancy between the longer median time to recovery to the lower limit of the reference range in Pickles' study and the shorter recovery times noted in the other studies, including ours, may be explained by the use of external beam radiotherapy to the prostate in Pickles' study. External beam radiotherapy delivers a higher cumulative dose of radiation to the testes compared to I-125 implants used in this study, which can further suppress Leydig cell function and delay testosterone recovery. ${ }^{19-23}$ For example, another study by Pickles and colleagues showed that testosterone levels can fall to about $83 \%$ of the baseline value 6 months after external beam radiotherapy to the prostate. ${ }^{22}$ Other limitations of this study include the lack of free or bio-available testosterone measurements, which are the bioactive forms of circulating testosterone that may directly influence the side effects of AST than total testosterone levels. Additionally, we did not record the time of the day at which the testosterone measurements were performed; it is known that testosterone levels should be drawn in the morning as levels tend to decrease later in the day.

We observed between one-fifth to one-third of patients did not have recovery of testosterone levels to baseline at the last follow-up of 18 months following completion of AST (Table 2). It is likely, however, that with longer follow-up, a higher proportion of men would have recovered their testosterone levels. In the study by D'Amico and colleagues, 9\% of men failed to experience a return of testosterone to baseline after long-term median follow-up of 7.5 years. ${ }^{6}$ However, only 1 patient in our entire cohort failed to recover their testosterone levels to the lower limit of the reference range. Others have reported full recovery of testosterone levels after AST. 7,24,25 Recovery of testosterone levels to the lower limit of the normal range is likely more clinically relevant than recovery to the baseline value. Thus, we conclude that the risk of permanent or prolonged androgen suppression with the use of 6 months of LHRH-A is negligible and acceptable.

Several investigators have reported a shorter time to recovery of testosterone levels in men under the age of 60 to 67 years. ${ }^{5,6,8,10}$ Acknowledging the same sample sizes, we also reported a faster testosterone recovery time (to baseline) in men under the age of 65 years, however, only in the group that received S-LHRH-A (Fig. 3). The median time to recovery of testosterone levels to baseline was 4 months versus 16 months for the $<65$ years and $\geq 65$ years of age groups, respectively (log-rank test, $p=0.038$ ). Although the Cox model hazard ratios for age $\geq 65$ years versus age $<65$ years showed that the older age group had longer times to testosterone recovery than the younger group, this was not statistically significant. 


\section{Conclusion}

We conclude that the current study did not have sufficient power to validate the hypothesis that using S-LHRH-A preparations will hasten recovery of testosterone, There was a trend, however, towards more rapid testosterone recovery, possibly in younger men. The median time to recovery of testosterone after cessation of AST is about 2 to 8 months after 6 months of AST use, depending on how recovery is defined. These results are particularly applicable to men who receive radical prostatectomy or brachytherapy, as these men tend to be healthier and younger with preserved baseline testosterone levels and negligible radiation scatter to the testes compared to men who receive external beam radiotherapy.

Competing interests: Dr. Pickles has received support from Abbott Laboratories within the last 3 years for meetings.

This paper has been peer-reviewed.

Acknowledgements: This study was funded by the Abbott CARO Uro-Oncologic Radiation Award (ACURA), created in partnership between Abbott Laboratories and Canadian Association of Radiation Oncology (CARO). We would also like to thank the BC Cancer Agency - Vancouver Island Radiation Therapy Business Unit for their assistance with research assistant support.

\section{References}

1. Bolla $M$, Collette L, Blank L, et al. Long-term results with immediate androgen suppression and external irradiation in patients with locally advanced prostate cancer (an EORTC study): a phase III randomised trial. Lancet 2002;360:103-6.

2. D'Amico A, Manola J, Loffredo M, et al. 6-month androgen suppression plus radiation therapy vs radiation therapy alone for patients with clinically localized prostate cancer: a randomized controlled trial. JAMA 2004;292:821-7.

3. Keating NL, O'Malley AJ, Smith MR. Diabetes and cardiovascular disease during androgen deprivation therapy for prostate cancer. J Clin Oncol 2006;24:4448-56.

4. Kintzel PE, Chase SL, Schultz LM, et al. Increased risk of metabolic syndrome, diabetes mellitus, and cardiovascular disease in men receiving androgen deprivation therapy for prostate cancer. Pharmacotherapy 2008;28:1511-22.

5. Gulley JL, Aragon-Ching JB, Steinberg SM, et al. Kinetics of serum androgen normalization and factors associated with testosterone reserve after limited androgen deprivation therapy for nonmetastatic prostate cancer. J Urol 2008;180:1432-7; discussion 1437.
6. D'Amico AV, Renshaw AA, Loffredo B, et al. Duration of testosterone suppression and the risk of death from prostate cancer in men treated using radiation and 6 months of hormone therapy. Cancer 2007; 1 10:1723-8.

7. Goldenberg SL, Bruchousky N, Gleave ME, et al. Intermittent androgen suppression in the treatment of prostate cancer: a preliminary report. Urology 1995;45:839-44; discussion 844-5.

8. Gulley JL, Figg WD, Steinberg SM, et al. A prospective analysis of the time to normalization of serum androgens following 6 months of androgen deprivation therapy in patients on a randomized phase III clinical trial using limited hormonal therapy. I Urol 2005;173:1567-71.

9. Murthy V, Norman AR, Shahidi M, et al. Recovery of serum testosterone after neoadjuvant androgen deprivation therapy and radical radiotherapy in localized prostate cancer. BJU Int 2006;97:476-9.

10. Pickles T, Agranovich A, Berthelet E, et al. Testosterone recovery following prolonged adiuvant androgen ablation for prostate carcinoma. Cancer 2002;94:362-7.

11. Nejat RJ, Rashid HH, Bagiella E, et al. A prospective analysis of time to normalization of serum testosterone after withdrawal of androgen deprivation therapy. J Urol 2000;164:1891-4.

12. Oefelein MG. Time to normalization of serum testosterone after 3-month luteinizing hormone-releasing hormone agonist administered in the neoadjuvant setting: implications for dosing schedule and neoadjuvant study consideration. J Urol 1998; 160:1685-8.

13. Blasko JC, Mate T, Sylvester JE, et al. Brachyytherapy for carcinoma of the prostate: techniques, patient selection, and clinical outcomes. Semin Radiat Oncol 2002:12:81-94.

14. Morris WJ, Keyes M, Palma D, et al. Evaluation of Dosimetric Parameters and Disease Response After (125) Iodine Transperineal Brachytherapy for Low- and Intermediate-Risk Prostate Cancer. Int J Radiat Oncol Biol Phys 2009;7:1432-8.

15. Rosen RC, Cappelleri JC, Gendrano N, 3rd. The International Index of Erectile Function (IIEF): a state-ofthe-science review. Int I Impot Res 2002; 14:226-44.

16. Kalbfleisch J, Prentice R. The statistical analysis of failure time data. New York: NY: Wiley; 2002.

17. Gleave ME, Goldenberg SL, Sullivan LD, et al. Recovery of testosterone levels after neoadiuvant hormone therapy - comparison of 3 vs 8 months treatment prior to radical prostatectomy. J Urol 2000;163(Suppl):292.

18. Petit JH, Gluck C, Kiger WS, 3rd, et al. Bicalutamide alone prior to brachytherapy achieves cytoreduction that is similar to luteinizing hormone-releasing hormone analogues with less patient-reported morbidity. Urol Oncol 2008;26:372-7.

19. Amies $\mathrm{CJ}$, Mameghan H, Rose A, et al. Testicular doses in definitive radiation therapy for localized prostate cancer. Int J Radiat Oncol Biol Phys 1995;32:839-46.

20. Tomic R, Bergman B, Damber JE, et al. Effects of external radiation therapy for cancer of the prostate on the serum concentrations of testosterone, follicle-stimulating hormone, luteinizing hormone and prolactin. J Urol 1983;130:287-9.

21. Daniell HW, Clark IC, Pereira SE, et al. Hypogonadism following prostate-bed radiation therapy for prostate carcinoma. Cancer 2001:91:1889-95.

22. Pickles $T$, Graham P. What happens to testosterone after prostate radiation monotherapy and does it matter? J Urol 2002;167:2448-52

23. Zagars GK, Pollack A. Serum testosterone levels after external beam radiation for clinically localized prostate cancer. Int I Radiat Oncol Biol Phys 1997;39:85-9.

24. Giberti C, Barreca T, Martorana G, et al. Hormonal pattern and testicular histology in patients with prostatic cancer after long-term treatment with a gonadotropin-releasing hormone agonist analogue. Eur Urol 1988; 15:125-7.

25. Linde R, Doelle GC, Alexander N, et al. Reversible inhibition of testicular steroidogenesis and spermatogenesis by a potent gonadotropin-releasing hormone agonist in normal men: an approach toward the development of a male contraceptive. N Engl J Med 1981;305:663-7.

Correspondence: Dr. Howard Huaihan Pai, BC Cancer Agency-Vancouver Island Centre, 2410 Lee Ave, Victoria, BC V8R 6V5; fax: 250-519 2018; hpai@bccancer.bc.ca 


\title{
A new dawn in prostate cancer management: Do we have the trials to support it?
}

\author{
D. Andrew Loblaw, MD, MSc, FRCPC, CIP \\ Department of Radiation Oncology, Odette Cancer Centre, Sunnybrook Health Sciences Centre, University of Toronto, Toronto, ON
}

See related article on page 173.

Cite as: Can Urol Assoc J 2011;5(3):180-1; D01:10.5489/cuaj.11098

$P$ ai and colleagues report a small randomized controlled trial (RCT) examining whether men who receive 6 months of neoadjuvant androgen deprivation therapy for cytoreduction recover faster whether they receive a monthly luteinizing hormone-releasing hormone agonist (LHRHa) or an injection every 3 months. ${ }^{1}$ Unfortunately, due to accrual and eligibility issues, the authors were not able to complete the study in a timely manner and only 46 of the planned 100 patients were available for data analysis. There was a difference in testosterone recovery ( 4 vs. 8 months), but this failed to reach statistical significance $(p=0.27)$ and was much smaller than was seen in the authors' previous retrospective study (8 vs. 16 months).

The fact that the authors failed to achieve the target sample size is the greatest symptom of the challenges we face with clinical trials. Clinical trials are scientifically and ethically the only way for medicine to evolve to meet the many challenges in our health care systems. Duley and colleagues identified a number of barriers to conducting phase 3 studies: inadequate funding, overly complex regulations producing needlessly complex trial procedures, excessive monitoring, over restrictive interpretation of privacy laws without evidence of subject benefit and inadequate understanding of methodology. ${ }^{2}$

Even if these barriers can be overcome, Dilts estimates that only 1 in 3 trials reach their accrue goals (D Dilts, personal communication 2009). Lara and colleagues would add patient and physician lack of equipoise to the above list. ${ }^{3}$ Given our climate of health care consumerism, the lack of equipoise is a particular challenge when evaluating interventions that are available off study - why, as a patient, would you subject yourself to a random allocation of treatment $A$ versus B when you can choose? This effect was seen in 3 high-profile Canadian-led prostate cancer RCTs that failed or are struggling to reach their accrual goals: (1) NCIC CTG's PR 10 study (SPIRIT: prostactectomy vs. brachytherapy), (2) OCOG PR1 (ELAAT: early vs.. deferred androgen ablation therapy) and (3) NCIC CTGs PR11 (START: active surveillance vs. radical treatment). We need to question whether we can complete a pragmatic RCT in prostate cancer. Are there other methodologies, like the patient preference trial, that may be appropriate to inform evidence-based policy decisions?

Getting back to the above study, we might ask why this study was done. Permanent seed brachytherapy is a single, outpatient procedure with a 1 -hour recovery time and available mature outcomes. Twelve-year biochemical diseasefree survival (bDFS) rates are $98 \%$ and $96 \%$ for low- and intermediate-risk disease. ${ }^{4,5}$ Sexual and overall quality of life (QOL) scores are better than prostatectomy with no worse bowel QOL. ${ }^{6}$ Investigators have reported that brachytherapy has better long-term control than external beam radiotherapy (EBRT) at median doses of 68 Gy (95 vs. $75 \%$ at 7 years bDFS $)^{7}$ or even at 81 Gy using intensity-modulated radiation therapy (IMRT) (95 vs. $89 \%$ at 7 years bDFS). ${ }^{8}$ Quality is important - the higher the dose to $90 \%$ of the prostate, the greater the likelihood of controlling the prostate-specific antigen. ${ }^{9}$ The problem with brachytherapy is that a good quality implant cannot be achieved in every man, particularly those with large $(>60 \mathrm{cc})$ prostates.

This is where cytoreduction comes in; 5-alpha reductase inhibitors (5-ARIs), antiandrogens + 5-ARIs or LHRHa can provide 17,31 and $40 \%$ volume reductions with variable degrees of libido loss, fatigue and hot flashes. ${ }^{10}$ However, most men are not keen to expose themselves to these side effects and the costs of these medications are significant, even short term.

A new question emerges: Can we safely biologically dose escalate radiotherapy doses in men with prostates larger than 
60 cc? Stereotactic EBRT techniques have been developed which require only 5 treatments, deliver biologically similar doses to brachytherapy, are well-tolerated, highly effective and can treat prostates up to 90 cc. ${ }^{11.12}$

Further follow-up is needed for these emerging technologies, but I believe we are in a renaissance in prostate cancer management. I predict that within the decade we will be able to demonstrate in clinical trials that 5 or less outpatient treatments will have a $99 \%$ success rate and less than $1 \%$ severe side effects. We just need to put our collective minds to the challenge and as androgen deprivation therapy is such an effective adjuvant, it should be considered as part of the potential solution.

\section{Competing interests: None declared.}

This paper has been peer-reviewed.

\section{References}

1. Pai HH, Pickles $T$, Keyes $M$, et al. Randomized study evaluating testosterone recovery using short versus long-acting luteinizing hormone releasing hormone agonists. Can Urol Assoc J 2011;5:173-9; DOl:10.5489/cuaj.10102

2. Duley L, Antman K, Arena J, et al. Specific barriers to the conduct of randomized trials. Clin Trials 2008:5:40-8.
3. Lara PN Jr, Higdon R, Lim N, et al. Prospective evaluation of cancer clinical trial accrual patterns: identifying potential barriers to enrollment. I Clin Oncol 2001;19:1728-33.

4. Butler WM, Stewart RR, Merrick GS. Evaluation of radiobiologic biochemical control in a large permanent prostate brachytherapy population from a single institution using AAPM TG-137 parameters. Brachytherapy 2011;10:16-28.

5. Taira AV, Merrick GS, Butler WM, et al. Long-term outcome for clinically localized prostate cancer treated with permanent intersititial brachytherapy. Int J Radiat Oncol Biol Phys 2011;79:1336-42.

6. Crook JM, Gomez-Ituriaga A, Wallace K, et al. Comparison of health-related quality of life 5 years after SPIRIT: Surgical Prostatectomy versus Interstitial Radiation Intervention Trial. J Clin Oncol 2010;29:362-8.

7. Pickles T, Keyes M, Morris WJ. Brachytherapy or conformal external radiotherapy for prostate cancer: a single-institution matched-pair analysis. Int J Radiat Oncol Biol Phys 2010;76:43-9.

8. Zelefsky MJ, Yamada Y, Pei X, et al. Comparison of tumor control and toxicity outcomes of high-dose intensity-modulated radiotherapy and brachytherapy for patients with favorable risk prostate cancer. Urology 2011;77:986-90.

9. Potters L, Roach lii M, Davis BJ, et al. Postoperative nomogram predicting the 9-year probability of prostate cancer recurrence after permanent prostate brachytherapy using radiation dose as a prognostic variable. Int J Radiat Oncol Biol Phys 2010;76:1061-5.

10. Quon H, Loblaw DA. Androgen deprivation therapy for prostate cancer-review of indications in 2010. Curr Oncol 2010;17 (Suppl 2):S38-44.

11. Boike TP, Lotan Y, Cho LC, et al. Phase I dose-escalation study of stereotactic body radiation therapy for low- and intermediate-risk prostate cancer. I Clin Oncol 2011;29:2020-6. Epub 2011 Apr 4.

12. Quon $\mathrm{H}$, Cheung $\mathrm{P}$, Cesta $\mathrm{A}$, et al. Phase 2 study of a five-fraction hypofractionated accelerated radiotherapy treatment for low risk localized prostate cancer: Toxicity results of pHART3. 2010 GU Cancers Symposium Proceedings 2010:abstract 48.

Correspondence: Dr. Andrew Loblaw, Department of Radiation Oncology, Odette Cancer Centre, Sunnybrook Health Sciences Centre, University of Toronto, 2075 Bayview Ave., Toronto, ON M4N 3M5; fax: 416-480-6002; andrew.loblaw@sunnybrook.ca 